\title{
Construcción de escenarios en GeoGebra en la movilización de conocimientos matemáticos por alumnos con altas habilidades/superdotados
}

\author{
Adrieli Cristine Bueno ${ }^{1}$ \\ adrielicbueno@gmail.com \\ https://orcid.org/0000-0001-5363-4099 \\ Maria Ivete Basniak ${ }^{1}$ \\ maria.basniak@ies.unespar.edu.br \\ https://orcid.org/0000-0001-5172-981X \\ ${ }^{1}$ Universidade Estadual do Paraná (UNESPAR, Brasil)
}

Recibido: 23/05/2020 Aceptado: 06/07/2020

\begin{abstract}
Resumen
En el contexto educacional, es posible utilizar diferentes recursos que pueden contribuir para el aprendizaje de matemática, estimulando el pensamiento lógico y creativo de los alumnos, en que es necesario considerar la relación instrumental de la acción del sujeto con el artefacto. Así, este trabajo investiga la movilización de conocimientos matemáticos en la construcción de escenarios en GeoGebra por alumnos con altas habilidades/superdotación bajo el soporte teórico de la Génesis Instrumental. Este abordaje teórico relaciona artefacto, instrumento y esquemas, y sugiere un modelo de aprendizaje instrumentado por la matemática. En ese contexto, el trabajo asume supuestos metodológicos de investigación y Design-Based Research (DBR), que agrega ventajas de las metodologías cualitativas y cuantitativas, en que los supuestos teóricos son utilizados para analizar la construcción de un escenario animado por un alumno con altas habilidades/superdotado. Los análisis hacen evidente que GeoGebra ha favorecido la realización y materialización de la tarea movilizando conocimientos matemáticos, em que la relación establecida entre álgebra y geometría es despegada. El alumno relacionó la matemática con las herramientas disponibles en GeoGebra, construyendo un nuevo escenario utilizando diferentes contenidos, que él ha comprendido desde la construcción realizada.
\end{abstract}

Palabras-clave: Altas habilidades/superdotación; Matemática Educativa; Génesis Instrumental.

\section{A construção de cenários animados no GeoGebra na mobilização de conhecimentos matemáticos por alunos com altas habilidades/superdotação}

\section{Resumo}

No contexto educacional, é possível utilizar diferentes recursos que podem contribuir para a aprendizagem da matemática, estimulando o pensamento lógico e criativo dos alunos, em que é necessário considerar a relação instrumental da ação do sujeito com o artefato. Assim, este trabalho investiga a mobilização de conhecimentos matemáticos na construção de cenários animados no GeoGebra por alunos com indicativo de altas habilidades/superdotação sob o aporte teórico da Gênese Instrumental. Essa abordagem teórica relaciona artefato, instrumento e esquemas, e sugere um modelo de aprendizagem instrumentada pela matemática. Neste contexto, o trabalho assume pressupostos metodológicos de investigação e pesquisa Design-Based Research (DBR), que agrega vantagens das metodologias qualitativas e das quantitativas, em que os pressupostos teóricos 
são usados para analisar a construção de um cenário animado por um aluno com altas habilidades/superdotação. As análises evidenciam que o GeoGebra favoreceu a realização e concretização da tarefa mobilizando conhecimentos matemáticos, em que a relação estabelecida entre álgebra e geometria é destacada. O aluno relacionou a matemática com as ferramentas disponíveis no GeoGebra, construindo um novo cenário utilizando diferentes conteúdos que compreendeu a partir da construção realizada.

Palavras-chave: Altas habilidades/superdotação; Educação Matemática; Gênese Instrumental.

\title{
Constructing animated scenarios in GeoGebra in mathematical knowledge mobilization by high skills/giftedness students
}

\begin{abstract}
In the educational context is possible using different resources that might contribute to mathematical learning, stimulating students' logical and creative thoughts, in which considering the instrumental relationship between the subject's action and the artifact is necessary. Thereby, this work investigates mathematics knowledge mobilization to construct animated scenarios in Geogebra by high skills/giftedness students with theoretical contribution by Instrumental Genesis. This theoretical approach relates artifact, instrument, scheme, and suggests a learning model instrumented by mathematics. In this context, the work uses research methodological assumptions and Design-Based Research (DBR) that aggregate advantages both from qualitative and quantitative methodologies, and theoretical assumptions are used to analyze an animated scenery construction by a skills/giftedness student. Analysis showed GeoGebra favored to perform and materialize the task through mathematical knowledge mobilization, in which the relation established between algebra and geometry is highlighted. The student related mathematics with tools available in GeoGebra, constructing a new scenery using different contents understood from the geometrical construction carried out.
\end{abstract}

Keywords: Skills/giftedness; Mathematics Education; Instrumental Genesis.

\section{Introdução}

Desde 1998, os Parâmetros Curriculares Nacionais para o Ensino de Matemática propuseram que o ensino de Matemática deveria "aproveitar ao máximo os recursos tecnológicos, tanto pela sua receptividade social como para melhorar a linguagem expressiva e comunicativa dos alunos" (Brasil, 1998, p. 46). Atualmente, recursos tecnológicos, didáticos e pedagógicos disponíveis, sejam computadores, tablets ou telefones celulares, podem contribuir para promover a aprendizagem dos alunos e suas interações, estimulando o pensamento crítico, lógico e criativo (Brasil, 2017). Nesse sentido, as Orientações Curriculares para o Ensino Médio (Brasil, 2006) enfatizam que, com softwares, os alunos têm a possibilidade de investigar conteúdos matemáticos, e que durante esse processo pensam matematicamente. Ainda nesse sentido, os aplicativos e softwares podem auxiliar 
alunos e professores possibilitando a visualização, testes e generalização, em um processo dinâmico por meio do qual se confronta teoria e prática (Paraná, 2008).

Nesse contexto, o software usado nesta pesquisa e que vem ganhando cada vez mais destaque é o GeoGebra, software livre, gratuito e de matemática dinâmica que pode ser utilizado para o ensino da matemática.

Uma das justificativas da utilização desse software é o fato de ele integrar ferramentas de forma algébrica e geométrica, o que "possibilita o desenvolvimento das atividades em vários registros de representações dos objetos matemáticos" (Abar e Alencar, 2013, p. 360). Isso provoca a associação "destas representações de forma simultânea" que "pode levar à construção ampla dos conceitos matemáticos envolvidos" (Notare e Basso, 2017a, p. 3).

Nesse sentido, trabalhamos desde agosto de 2017 com alunos com altas habilidades/superdotação em matemática da Sala de Recursos Multifuncional II de uma escola do Paraná. Por meio de projetos de iniciação científica envolvendo o GeoGebra e a construção de cenários animados utilizando conteúdos de matemática, obtêm-se resultados em relação à compreensão dos alunos de conceitos matemáticos, entre os quais o de funções (Bueno e Basniak, 2018). As pesquisas desenvolvidas até então despertaram outras questões de investigação, entre as quais salientamos o objetivo deste trabalho, que é investigar a mobilização de conhecimentos matemáticos na construção de cenários animados no GeoGebra por alunos com indicativo de altas habilidades/superdotação, sob o aporte teórico da Gênese Instrumental.

Nesse contexto, observamos que, “[...] durante o trabalho conjunto, os professores e alunos recorrem a signos (palavras, gestos, inscrições de todo tipo, etc.) e artefatos (calculadora, computador, software de aplicação, etc.) portadores de determinadas conceitualidades que afetam os significados produzidos na aula" (Pietro G. e Araújo, 2019, p. 2). Por isso é necessário considerar a importância instrumental no processo de aprendizagem.

Para tanto, nesta pesquisa, apoiamo-nos nas investigações sobre a Gênese Instrumental de Rabardel (2002), que relaciona artefato, instrumento e esquemas. Assim, a Gênese Instrumental sugere um modelo de aprendizagem instrumentada pela matemática, que se fundamenta na relação entre artefato e instrumento. 
Dessa forma, o software GeoGebra pode possuir status de artefato ou de instrumento. Antes de ser utilizado pelo sujeito, o software possui status de artefato, mas quando utilizado para construção de cenários animados, o sujeito emprega conceitos matemáticos que sustentam sua atividade e utiliza as ferramentas disponíveis; então, o software passa a ter status de instrumento.

Salientamos que utilizamos "[...] o software GeoGebra não apenas como mais um recurso tecnológico, mas, sim, como um recurso que colabore no desenvolvimento de conceitos matemáticos, uma vez que, por si só, o software não faz Matemática" (Abar e Alencar, 2013, p. 352), sendo necessários o conhecimento e a ação do sujeito.

Já os esquemas abarcam estratégias e conteúdos mobilizados durante as construções das animações, pois Rabardel (2002, p. 51), citando Piaget, define os esquemas de utilização como "o grupo estruturado de características generalizáveis da ação que permite que a mesma ação seja repetida ou aplicada a novos conteúdos”.

$\mathrm{Na}$ seção que segue, discutimos os elementos teóricos que fundamentam este trabalho.

\section{Gênese Instrumental}

A Gênese Instrumental (Rabardel, 2002) apoia-se na teoria da ergonomia cognitiva relativa a processos mentais, como raciocínio e memória, os quais permitem estudar ações e interações dos indivíduos com os elementos de um sistema. Essa abordagem diferencia artefato, instrumento e os processos que se desenvolvem na transformação progressiva do artefato em instrumento. Esse processo não é único e nem definitivo, mas decorre da construção em que ocorre a integração entre as particularidades dos artefatos, sejam as potencialidades e limitações, e as atividades do sujeito.

Para Rabardel (1995), o sujeito, o instrumento e o objeto são centrais na Gênese Instrumental. Isto porque o sujeito, que pode ser o operador, trabalhador ou agente, utiliza artefatos, máquinas, ferramentas ou sistemas para realizar uma ação com base em seus conhecimentos, com o apoio do artefato.

Um artefato é um objeto material ou simbólico destinado a dar sustento à atividade do sujeito na execução de um certo tipo de tarefa (García-Cuéllar e Martínez-Miraval, 2018). Segundo Rabardel (1995), antes da atividade, o artefato é uma ferramenta neutra, sem função para o indivíduo, e somente após a atividade e a manipulação o recurso passa a ser um objeto 
tecnológico com significados e funções, pois "essa interação mobiliza conhecimentos do sujeito que vão sendo modificados na sua estrutura cognitiva" (Pachêco et al., 2018, p. 8).

Então, quando o indivíduo faz uso de um determinado artefato para realizar ou atingir objetivos de tarefas, e ainda compreende suas características e funcionalidades, o artefato passa a ser denominado instrumento, para o indivíduo. Logo, “o instrumento como artefato é constituído no(s) uso(s) que o sujeito faz dele. Dessa forma, os usos do artefato dependem, também, das necessidades e objetivos do usuário" (Abar e Alencar, 2013, p. 353).

Portanto, "um artefato não é um instrumento acabado" (Rabardel, 2002, p. 51), pois os artefatos evoluem de acordo com as necessidades ou objetivos do operador. Rabardel (2002) destaca que, por mais que os projetistas tenham idealizado o uso do artefato, muitas vezes ele ultrapassa as expectativas, criando possibilidades para além do design inicial proposto, funções previstas ou planejadas. Ainda de acordo com o autor, "a usabilidade de um artefato vem de um grupo de propriedades, e não de apenas uma" (Rabardel, 2002, p. 71). Essas propriedades podem ser combinadas de várias maneiras, e geram novos resultados.

De acordo com Bannon e Bodker (1991, apud Rabardel, 2002, p. 18), “[...] os artefatos existem na atividade e são constantemente transformados por atividade, eles não devem ser analisados como coisas, mas como mediadores do uso. Os artefatos não são apenas meios individuais". Logo, o artefato dá suporte à atividade do sujeito que realizará a tarefa proposta ou planejada, utilizando esquemas, de forma que, durante esse processo, o artefato possa ser adaptado. Para Rabardel (2002), o esquema é um todo, com elementos dependentes, que é utilizado e generalizado conforme o conteúdo em que é aplicado. A compreensão de Rabardel (1995) para conceituar esquemas apoia-se na teoria de Vergnaud (1990, apud García-Cuéllar, 2019), para quem um esquema é uma organização invariante da conduta do sujeito para uma classe determinada de situações. Então, quando o sujeito tenta utilizar um esquema já constituído, mas a situação em questão não lhe permite ter êxito, o

[...] esquema será, assim, progressivamente adaptado para gerenciar o movimento do objeto até que um novo esquema seja formado [...]. O novo comportamento formado é finalmente sustentado por um esquema principal que incorpora uma série de esquemas (Rabardel, 2002, p. 56).

De maneira geral, esquemas são ideias e organizações interativas que o indivíduo mobiliza para alcançar o objetivo da tarefa, ou seja, para chegar em respostas. Assim, segundo o autor, os esquemas são relacionados a um artefato e "são organizadores da ação, 
utilização, implementação e uso do artefato" (Rabardel, 2002, p. 67). Logo, são relativos a características e propriedades do próprio artefato, e ele é considerado o meio de ação. Rabardel (2002) ressalta que, "no entanto, os esquemas de utilidade não podem ser aplicados diretamente. Eles devem ser adaptados à especificidade de cada situação" (p. 67). Piaget e Beth (1961), citados por Rabardel (2002), evidenciam que os esquemas são um conjunto estruturado de características que surgem quando o comportamento, seja simples ou não, provoca um esforço recorrente ou repetitivo que o esquematiza.

O instrumento é composto do artefato e de esquemas, que podem estar associados um ao outro ou podem ter uma relação de independência relativa. Como exemplo, é imaginável que um artefato esteja associado a vários esquemas de utilização que, por vezes, podem desempenhar distintas funções, como é o caso de dar golpes com uma chave inglesa, função que deveria ser de um martelo (Rabardel, 2002). Portanto, “[...] não há instrumento sem artefato" (Rabardel, 2002, p. 69). Desse modo,

Para os sujeitos, um artefato é enriquecido pelas situações de ação em que esteve circunstancialmente envolvido [...]. É assim que poderíamos chamar [...] o campo instrumental do artefato, para o sujeito: o conjunto de esquemas de utilização de artefatos nos quais ele pode ser introduzido para formar um instrumento; o conjunto de objetos em que permite que o sujeito atue (Rabardel, 2002, p. 69).

Então, o instrumento é o que o sujeito constrói a partir do artefato (García-Cuéllar e Salazar, 2019). Segundo Rabardel (2002, p. 50), “um instrumento é considerado por unanimidade uma entidade intermediária [...] entre duas entidades: sujeito, ator, usuário do instrumento e objeto da ação". Assim, o instrumento surge a partir do artefato, por meio da ação do sujeito que utiliza esse meio para criar ou fixar o conhecimento humano adquirido (Rabardel, 2002). Logo, somos

[...] levados a estender a definição de Mounoud (1970) de acordo com a qual um instrumento pode ser qualquer objeto que o sujeito associe à sua ação para executar uma tarefa. Não é apenas o "objeto" associado e associável pelo sujeito à sua ação para a execução da tarefa, mas também os esquemas de utilização que permitirão a introdução de um instrumento como um componente funcional do sujeito (Rabardel, 2002, p. 68).

Rabardel (2002) evidencia que o instrumento não é somente uma ação do sujeito no artefato, mas é uma criação ou construção. Os instrumentos desenvolvidos podem ser temporários e/ou curtos, relacionados unicamente a situações ou circunstâncias específicas, como podem também ser duráveis e/ou usados como meio para ações futuras (Rabardel, 2002). "Assim, o instrumento como um todo, bem como cada um dos seus componentes, é uma forma de experiência capitalizada, ou conhecimento" (Rabardel, 2002, p. 68). 
De acordo com o autor, um mesmo artefato pode ser utilizado por um grupo de indivíduos para desenvolver uma tarefa igual, seja ela comum ou compartilhada. Assim, a análise de esquemas recorridos durante o desenvolvimento de atividades no instrumento não deve ser limitada a somente um sujeito, mas a uma atividade coletiva. Entretanto, o “instrumento é uma construção individual para cada sujeito, pois um mesmo artefato pode se transformar em instrumentos distintos, dependendo de quem o usa e quais esquemas utilizam sobre o mesmo" (Pachêco et al., 2018, p. 8). Isto porque "um instrumento não existe 'por si só'; o artefato se transforma em um instrumento para um determinado sujeito quando este o incorpora às suas atividades" (Bittar, 2011, p. 160).

Dessa forma, "o sujeito (S) é quem pensa e conduz a operação direcionada sobre o objeto, por sua vez, o instrumento (I) é o mediador entre o sujeito e objeto, já o objeto (O) é o receptor de toda a ação, ou seja, é para ele que a ação é dirigida de todo o processo" (Pachêco et al., 2018, p. 5). Logo, existe uma relação entre objeto-sujeito (instrumentação) e a relação sujeito-objeto (instrumentalização), em que o instrumento é o meio da ação dirigida sobre o objeto. Rabardel (2002) discute e diferencia essa relação, definindo a instrumentalização e a instrumentação na Gênese Instrumental.

A instrumentalização é o processo que parte do sujeito para o artefato (sujeitoobjeto), durante o qual são utilizadas propriedades e ferramentas do próprio artefato, e permitem ao sujeito o domínio e ajustes do artefato de acordo com as finalidades ou demandas. Assim, "consiste em um progressivo reconhecimento das potencialidades e das limitações do artefato por parte do sujeito" (Notare e Basso, 2017a, p. 2). Também durante esse procedimento, o sujeito modifica, adapta e transforma o artefato para que seja empregado a uma série de tarefas.

Logo, a instrumentalização pode ser definida como "um processo no qual o sujeito registra as propriedades do artefato. Esse processo está fundamentado nas características e propriedades intrínsecas do artefato e lhes confere um status alinhado à ação em andamento e à situação" (Rabardel, 2002, p. 80). Por fim, destacamos que existem dois níveis no processo de instrumentação: "o primeiro tem uma característica local, ou seja, o artefato é instrumentalizado momentaneamente. No segundo nível, a função adquirida se conserva de maneira durável como propriedade do artefato, portanto a instrumentalização é durável ou permanente" (Neto e Silva, 2017, p. 110). 
Já a instrumentação (objeto-sujeito) é realizada pelo usuário e direcionada a ele mesmo, estando relacionada com a emergência, manifestação e progresso dos esquemas de utilização e de ação instrumental (Rabardel, 2002). Durante o desenvolvimento de tarefas ou operações, o sujeito elabora esquemas para utilizar no artefato e gerar instrumentos, mas, por vezes, o artefato retorna elementos que fazem o sujeito pensar sobre o que deverá ser feito. "É por uma evolução dos esquemas de exploração que os instrumentos do especialista se diferenciam dos do iniciante. Isso é instrumentação" (Rabardel, 2002, p. 80).

Segundo Bellemain e Trouche (2018, p. 109), “estes processos não são independentes um do outro, eles são entrelaçados" e inseparáveis, mas podemos diferenciá-los tomando o termo instrumentação "para designar aspectos do processo de gênese instrumental orientado para o próprio sujeito", e instrumentalização "para processos direcionados ao artefato" (Rabardel, 2002, p. 78). Segundo o autor,

\footnotetext{
Os processos de instrumentação dizem respeito ao surgimento e evolução dos componentes do artefato do instrumento: seleção, reagrupamento, produção e instituição de funções, [...] atribuição de propriedades, transformação do artefato (estrutura, funcionamento etc.) [...]. Os processos de instrumentação são em relação ao surgimento e evolução dos sistemas de utilização e ação mediada por instrumento: sua constituição, sua funcionalidade, sua evolução por adaptação, coordenação combinação, inclusão e assimilação recíproca, a assimilação de novos artefatos para regimes já constituídas, etc. (Rabardel, 2002, p. 79).
}

Conforme Rabardel (2002), os dois processos, instrumentação e instrumentalização, derivam do sujeito, que só estará instrumentalizado quando aprender a utilizar um artefato, e instrumentado quando desenvolver trabalhos manipulando o artefato; embora, em determinada situação, um dos dois possa ser dominante ou o único que se manifeste.

Ambos os processos colaboram para "a evolução do instrumento, para a reorganização e modificação dos esquemas de utilização do sujeito, permitindo a estruturação de sua ação e a participação da formação dos conceitos matemáticos” (Abar e Alencar, 2013, p. 355). Ressaltamos, também, que o instrumento surge individualmente a partir das experiências do sujeito, quando ele elabora esquemas com o uso do artefato em suas tarefas. Logo, "um mesmo artefato transforma-se em um instrumento diferente para cada sujeito, a partir de esquemas de utilização particulares" (Notare e Basso, 2017b, p. 2).

\section{Gênese Instrumental e os cenários animados}

Nesta pesquisa, os cenários animados partem de construções no software GeoGebra, empregando elementos matemáticos. Com o controle deslizante, pode-se determinar uma 
variável numérica dentro de um intervalo pré-estabelecido pelo operador, que varia de acordo com um incremento, também determinado pelo operador. Dessa forma, a construção ganha dinamicidade e movimento. Então, quando um objeto criado no software depende de um controle deslizante e o usuário altera o valor desse controle, que pode ser feito pela ferramenta animar, determinados objetos da construção se movem, o que permite que a construção final se constitua como cena animada.

Assim, as pesquisadoras estruturaram o Quadro 1 articulando elementos teóricos que fundamentam a Gênese Instrumental a descritores identificados em análises iniciais do desenvolvimento dos cenários, realizadas no primeiro período da pesquisa.

Quadro 1: Elementos da Gênese Instrumental

\begin{tabular}{|c|c|c|}
\hline $\begin{array}{l}\text { Elementos da } \\
\text { Gênese } \\
\text { Instrumental } \\
\end{array}$ & Características & $\begin{array}{l}\text { Descritores a serem considerados em relação aos } \\
\text { cenários animados }\end{array}$ \\
\hline Artefato & $\begin{array}{l}\text { O objeto sem ação do } \\
\text { sujeito. }\end{array}$ & $\begin{array}{l}\text { O GeoGebra assume status de artefato para o sujeito } \\
\text { quando ele: } \\
\text { - Apenas observa as ferramentas do artefato; } \\
\text { - Associa a matemática como comandos. }\end{array}$ \\
\hline Instrumento & $\begin{array}{l}\text { O objeto como } \\
\text { suporte/sustento/meio } \\
\text { para a atividade. }\end{array}$ & $\begin{array}{l}\text { O GeoGebra assume status de Instrumento para o } \\
\text { sujeito quando ele: } \\
\text { - A partir do artefato, consegue criar/adaptar os } \\
\text { cenários animados; } \\
\text { - Utiliza as ferramentas disponíveis no artefato para } \\
\text { produzir algo; } \\
\text { - Se apropria das características e potencialidades do } \\
\text { software; } \\
\text { - Consegue representar elementos matemáticos de } \\
\text { forma algébrica e/ou gráfica; } \\
\text { - Relaciona a matemática por trás dos comandos } \\
\text { matemáticos. }\end{array}$ \\
\hline Esquemas & $\begin{array}{l}\text { Generalização; } \\
\text { Adaptação; } \\
\text { Atividade. }\end{array}$ & $\begin{array}{l}\text { O aluno mobiliza estratégias e conteúdos durante as } \\
\text { construções das animações; } \\
\text { O aluno utiliza o conteúdo matemático e consegue } \\
\text { empregá-lo nos cenários; } \\
\text { O aluno consegue criar estratégias para novas } \\
\text { construções com base nas experiências vivenciadas; } \\
\text { O aluno cria cenários animados com potencial para } \\
\text { vários conteúdos matemáticos; } \\
\text { No coletivo: os alunos dialogam para partilhar ideias } \\
\text { e hipóteses para atender objetivos comuns. }\end{array}$ \\
\hline Instrumentação & $\begin{array}{l}\text { Parte do sujeito para } \\
\text { ele mesmo; como o } \\
\text { artefato afeta o sujeito. }\end{array}$ & $\begin{array}{l}\text { O sujeito: } \\
\text { - Desenvolve trabalhos manipulando o artefato; } \\
\text { - Estabelece relações entre a representação algébrica } \\
\text { e gráfica; } \\
\text { - Realiza todo o processo de construção e } \\
\text { manipulação do cenário utilizando corretamente as } \\
\text { ferramentas do artefato para chegar no objetivo; } \\
\text { - Utiliza o artefato como meio para realização e } \\
\text { concretização de tarefas, e mobiliza o } \\
\text { conhecimento matemático. }\end{array}$ \\
\hline
\end{tabular}




\begin{tabular}{|c|c|c|}
\hline Instrumentalização & $\begin{array}{l}\text { Parte do sujeito para o } \\
\text { artefato; forma como o } \\
\text { sujeito afeta o artefato. }\end{array}$ & $\begin{array}{l}\text { O sujeito: } \\
\text { - Compreende o funcionamento e manipula o } \\
\text { artefato; } \\
\text { - Tem noção das possibilidades e limites do } \\
\text { software; } \\
\text { - Personaliza o artefato de acordo com suas } \\
\text { necessidades; } \\
\text { - Investiga os componentes do artefato e suas } \\
\text { funcionalidades; } \\
\text { - Explora as potencialidades dos recursos } \\
\text { disponíveis no artefato. }\end{array}$ \\
\hline
\end{tabular}

Fonte: Elaborado pelas autoras, 2020

Na seção que segue, explicitamos o contexto em que foi realizada a pesquisa e a metodologia adotada para este trabalho, assim como o episódio de aula escolhido para a análise.

\section{Contexto e pressupostos metodológicos}

Trata-se de uma pesquisa qualitativa de cunho interpretativo pautada nos pressupostos da Design Basic Reserch (DBR) que, segundo Matta, Silva e Boaventura (2014), citando Mckenney e Reeves (2012), elencam cinco características da DBR: teoricamente orientada, intervencionista, colaborativa, fundamentalmente responsiva e iterativa.

Em relação à primeira característica, a de ser teoricamente orientada, a DBR assume que as teorias são ponto de partida, de chegada e de investigação. Nesse sentido, realizamos estudo teórico com base da Gênese Instrumental/Instrumentação (Rabardel, 2002), como apresentado e discutido na seção anterior, que culminou com a construção do Quadro 1. O referido quadro norteou as análises, o que está diretamente relacionado à segunda característica da DBR, de ser intervencionista. Isto porque se utiliza o fundamento teórico escolhido e o diálogo com o contexto de aplicação para que a pesquisa desenvolva uma aplicação que irá intervir no campo das práxis pedagógicas, e pretende produzir produtos educacionais e outros materiais.

Os alunos iniciaram sua participação em diferentes anos, mas no período em que ocorreram as intervenções apresentadas neste trabalho, agosto de 2019, participavam do projeto cinco alunos do sétimo ao nono ano do Ensino Fundamental (E.F.) e uma aluna do primeiro ano do Ensino Médio (E.M.). Esses alunos apresentavam altas habilidades/ superdotação em diferentes áreas, como pode ser observado no Quadro 2, abaixo. Os nomes 
dos alunos neste trabalho são fictícios para preservar suas identidades. Os encontros foram registrados por meio de gravações de áudio e vídeo.

Quadro 2: Dados dos alunos participantes da pesquisa em 2019

\begin{tabular}{|c|c|c|c|}
\hline Aluno & $\begin{array}{c}\text { Ano escolar } \\
\text { em 2019 }\end{array}$ & $\begin{array}{c}\text { Início no projeto e ano escolar em que } \\
\text { estava }\end{array}$ & $\begin{array}{c}\text { Altas Habilidades/ } \\
\text { Superdotação }\end{array}$ \\
\hline Laura & $1^{\circ}$ ano E.M. & Agosto de 2017 , estava no $8^{\circ}$ ano E.F. & Exatas \\
\hline Murilo & $9^{\circ}$ ano E.F. & Agosto de 2017 , estava no $7^{\circ}$ ano E.F. & Exatas \\
\hline Willian & $9^{\circ}$ ano E.F. & Março de 2018 , estava no $8^{\circ}$ ano E.F. & Exatas \\
\hline Gael & $8^{\circ}$ ano E.F. & Março de 2019 , estava no $8^{\circ}$ ano E.F. & Área acadêmica \\
\hline Kaique & $7^{\circ}$ ano E.F. & Agosto de 2018 , estava no $6^{\circ}$ ano E.F. & Exatas \\
\hline Eric & $7^{\circ}$ ano E.F. & Março de 2019 , estava no $7^{\circ}$ ano E.F. & Produtivo e criativo \\
\hline \multicolumn{3}{r}{ Fonte: Autoras, 2020}
\end{tabular}

Todos os alunos participantes já haviam realizado construções no GeoGebra porque participaram do projeto no(s) ano(s) anterior(es). Então, foi proposto que construíssem cenários animados planejados e completamente estruturados por eles, representando o cenário que desejassem como, por exemplo, de um desenho animado, um super-herói, ou outro a sua escolha. Para isso, os alunos deveriam utilizar diversos conteúdos matemáticos já estudados, tanto em sala de aula como no projeto.

Os sete encontros com os alunos duraram aproximadamente duas horas e quarenta minutos. Foram utilizados três encontros para que os alunos elaborassem as construções livres e as finalizassem. A aluna Laura e o aluno Eric construíram a animação juntos, e os alunos Murilo e Kaique construíram cada um a sua. Os demais alunos não compareceram ao encontro nesse dia. Após todos finalizarem, no quarto encontro iniciaram as apresentações da aluna Laura e do aluno Kaique para os demais alunos. Nos encontros quinto e sexto, o aluno Murilo construiu parte de sua animação com os demais alunos, sendo necessários mais trinta minutos do sétimo encontro. Nas apresentações, os alunos deveriam explicar aos demais colegas como realizaram a construção do cenário elaborado e os conteúdos matemáticos envolvidos. Durante essas aulas, tanto na construção do cenário como nas apresentações, os alunos eram questionados sobre os conteúdos e estratégias desenvolvidas.

O aluno Murilo construiu a animação Arqueiro $1^{1}$ (Figura 1), um boneco atirando uma flecha. O corpo do boneco foi construído com polígonos e uma circunferência. Ao iniciar a animação, enquanto o braço esquerdo do boneco fica parado, segurando o arco, o braço direito movimenta-se puxando a flecha. Quando o braço direito atinge determinada posição, a flecha é disparada, finalizando a animação. Para a construção, o aluno utilizou os

\footnotetext{
${ }^{1}$ A animação pode ser vista em 〈https://www.geogebra.org/m/vbkjwmx9>.
} 
seguintes conteúdos: coordenadas cartesianas, função de primeiro grau (crescente, decrescente e constante), lógica, domínio, imagem, programação e expressões algébricas. Porém, durante a apresentação foi observado, pela pesquisadora, que o aluno poderia ter utilizado outra estratégia, porque a animação ficou muito extensa e repetitiva. Então, no sétimo encontro foi proposto a todos os alunos que construíssem novamente a animação Arqueiro, mas utilizando outra estratégia e conteúdos matemáticos para isto, podendo partir do que foi proposto pelo aluno Murilo, acrescentando ou retirando elementos para que a animação ficasse menos repetitiva. Foi essencialmente por este motivo que selecionamos esse episódio para análise, pois os alunos tiveram que mobilizar estratégias e meios para atingir o objetivo proposto, de construir a animação Arqueiro novamente, a partir de suas ideias, de forma que a pesquisadora somente daria apoio e auxiliaria quando fosse necessário por meio de questionamentos ou intervenções.

Figura 1: Construção Arqueiro1

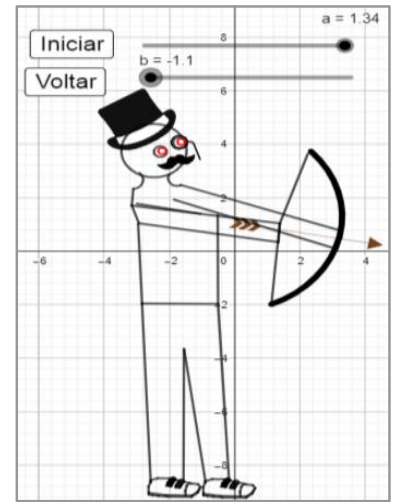

Fonte: Elaborada pelas autoras (2020)

Destacamos, ainda, que selecionamos a construção realizada pelo aluno Kaique para a análise devido ao fato de esse aluno estar no sétimo ano do Ensino Fundamental e ter ingressado no projeto em agosto de 2018, quando estava no sexto. Esse aluno pertence a uma família com dificuldades econômicas e, por consequência, com pouco acesso à cultura, livros e recursos tecnológicos. O aluno não possui celular e sua primeira experiência em trabalhar com o computador foi nos encontros do projeto. Portanto, apresentou muitas dificuldades, inicialmente de adaptação, porque não havia estudado muitos conteúdos que já haviam sido trabalhados com os outros alunos. Ainda, o software configurou-se como um desafio a mais, visto que o aluno nunca havia trabalhado com o computador. Por esses motivos que selecionamos a construção desse aluno para a análise neste trabalho, pois acreditamos que ele conseguiu se adaptar com o computador e o software durante sua participação no projeto, demonstrando considerável evolução durante os encontros, e passou a manifestar habilidade 
em usar o artefato e criar cenários animados sozinho, manipulando o software. Durante os encontros que participou, o aluno teve contato com os conteúdos de funções de primeiro grau, segundo grau, trigonométricas, exponencial, logarítmica, função por partes, lógica e expressões algébricas por meio das animações.

Entretanto, salientamos que esse episódio faz parte de uma pesquisa mais ampla, que envolve outros pesquisadores com objetivos distintos e intervenções realizadas com alunos com altas habilidades/superdotação de outros dois grupos diferentes. Neste contexto, os três pesquisadores responsáveis pelas pesquisas e intervenções realizavam encontros semanais para planejar e discutir as construções e intervenções a serem desenvolvidas com cada grupo de alunos, discutindo possibilidades para atingir os objetivos de cada pesquisa. Nesse sentido, a pesquisa está alinhada à terceira característica da DBR, de ser colaborativa, o que implica em ser sempre conduzida em meio a vários graus de colaboração. O desenvolvimento e a busca por uma aplicação que seja solução concreta para problemas dados obrigam a colaboração de todos os envolvidos: investigador, comunidade e pessoas que se relacionam. Também está diretamente relacionada com a sua quarta característica, de ser fundamentalmente responsiva, ou seja: é moldada pelo diálogo entre os saberes dos participantes, o conhecimento teórico, suas interpretações advindas da literatura, e pelo conjunto dos testes e validações diversas realizadas em campo. Assim, as intervenções e análises foram permeadas por discussões com outros pesquisadores, alunos envolvidos na pesquisa, e a professora da sala de recursos que acompanha as intervenções, a fim de atender a quinta característica da DBR, de ser iterativa, pois é uma metodologia voltada para aperfeiçoar soluções práticas.

$\mathrm{Na}$ seção seguinte, discutimos a construção da segunda versão da animação Arqueiro $^{2}$, buscando identificar e relacionar as ações do aluno Kaique com os elementos da Gênese Instrumental de Rabardel (2002), apresentando excertos do episódio que sustentam nossas análises.

\section{Análise do episódio da construção Arqueiro 2}

O aluno Kaique iniciou sua animação construindo a calça e a camiseta do boneco utilizando a ferramenta polígono, e plotando pontos sem coordenadas específicas no plano, de maneira que apenas fosse possível identificar as peças de roupa. Logo, podemos observar

\footnotetext{
${ }^{2}$ Animação disponível em: https://www.geogebra.org/m/b9z2akdy
} 
que o aluno consegue utilizar a ferramenta do artefato sem necessitar de auxílio, mas sem utilizar critérios matemáticos para isto. Na sequência, o aluno Kaique construiu os braços do boneco (Figura 2) e utilizou corretamente o que viu na apresentação do aluno Murilo, em relação à ferramenta Polígono, reproduzindo sozinho em sua construção. Quando questionado sobre como realizou a construção e os critérios matemáticos utilizados, o aluno respondeu que não teve nenhum critério inicial, como pode ser observado no excerto abaixo:

Pesquisadora: Como você fez?

Kaique: Não sei.

Pesquisadora: Não sabe?

Kaique: Eu só ativei o polígono e plim plim plim [mostra os pontos plotados no gráfico que formam os polígonos].

Pesquisadora: E como você colocou esses pontos?

Kaique: Ah, eu fui clicando.

Pesquisadora: Mas com relação à matemática? [...]. Por que o segmento AB é menor que o DE, se são as pernas?

Kaique: Não sei, a barra da calça de um é maior.

Pesquisadora: Qual foi o seu critério para fazer dessa forma?

Kaique: Nenhum.

Figura 2: Esboço do corpo do boneco

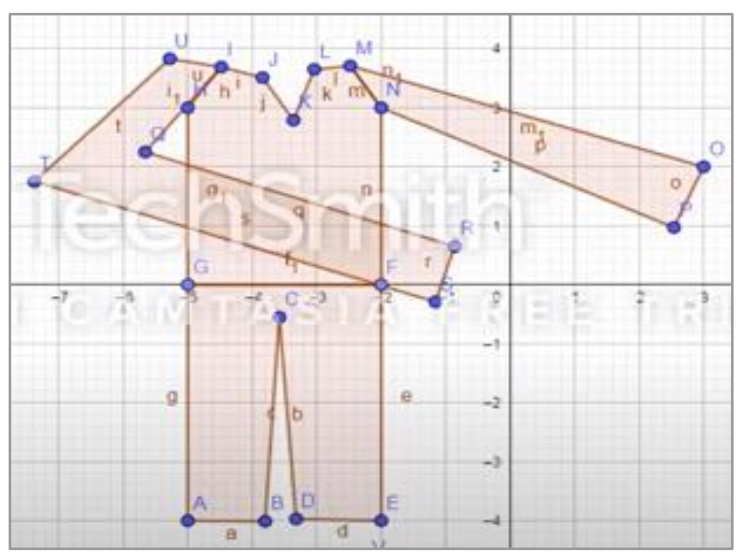

Fonte: Elaborada pelas autoras (2020)

Em seguida, ele calculou mentalmente e alterou as coordenadas dos pontos B e D do polígono que forma a calça, para que do ponto A para B e do ponto D para E se mantivesse a mesma distância (Figura 3). O aluno Kaique citou que os dois segmentos estavam simétricos, mas não exibiu argumentos suficientes para afirmar isto, como pode ser observado no excerto abaixo.

Kaique: Agora está simétrico, professora.

Pesquisadora: A blusa também está simétrica?

Kaique: Espera um pouco.

Pesquisadora: Mas está mudando os pontos ou ...?

Kaique: Eu estou modificando [...]. Porque, olhe aqui, do A [com coordenadas (-5,-4)] ao $B$ [com coordenadas $(-3.75,-4)$ ], -5 ao $-3,75$ [com relação ao eixo x] dá 1,25, $e$ [com relação as coordenadas $\mathrm{D}=(-3.25,-4)$ e $\mathrm{E}=(-2,-4)]$ do $-3,25$ ao -2 é 1,25 também [com relação ao eixo $\mathrm{x}]$. 
Pesquisadora: Como? Não entendi.

Kaique: Olhe aqui, do -5 ao $-3,75$...

Pesquisadora: $O$ que que é esse -5?

Kaique: Esse -5 é onde está o A [no eixo x], e esse -3,25 [onde está o $\mathrm{B}$ no eixo x] é exatamente onde está isso aqui [aponta para o ponto B na tela do computador]. De -5 até 3,75 tem a diferença de 1,25, e do D ao E, de -3,25 ao -2 tem a diferença de 1,25 também, entendeu?

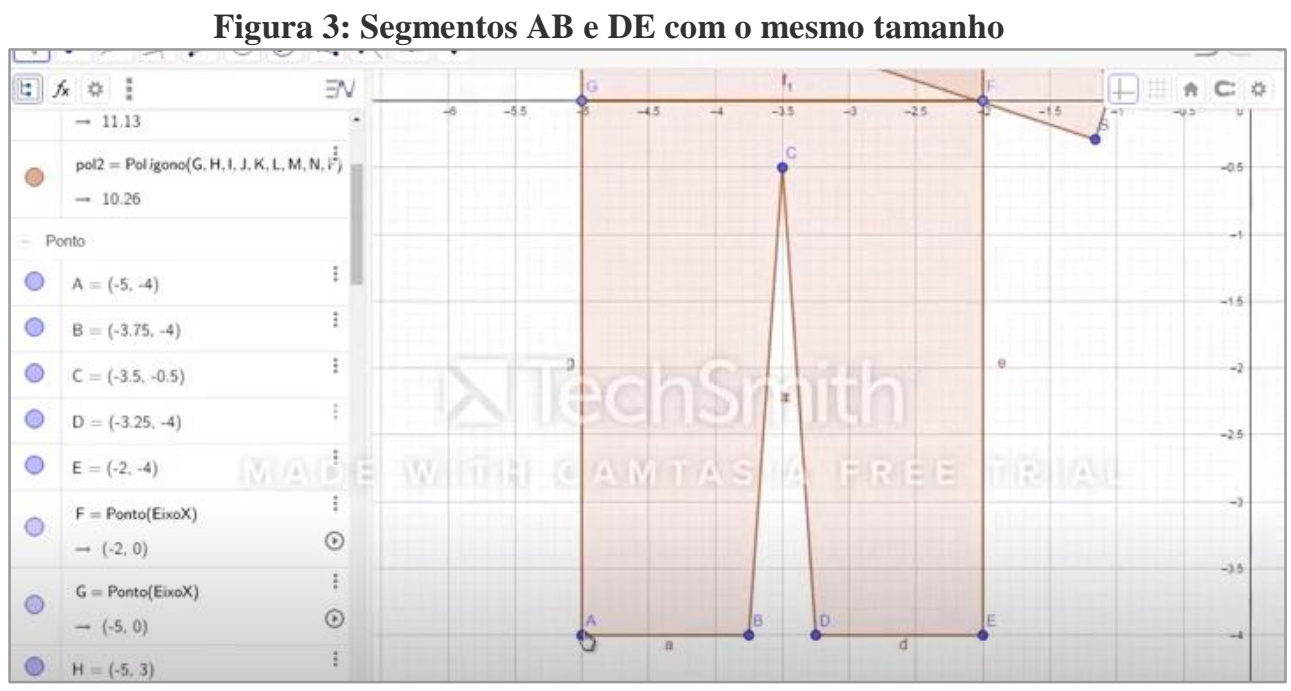

Fonte: Elaborada pelas autoras (2020)

Logo, ele sabe que os dois segmentos possuem a mesma medida porque calcula com base nas coordenadas. A partir disso, afirmamos que o aluno mobilizou estratégias para que os segmentos do polígono tivessem o mesmo tamanho, mas não necessariamente que ficassem simétricos. Também observamos que ele estabeleceu relações entre a parte algébrica com a gráfica do software porque, ao alterar os valores das coordenadas na janela de álgebra, o polígono que estava na janela gráfica também foi alterado.

Então, a pesquisadora solicitou que o aluno explicasse por que as distâncias não eram negativas, já que estava trabalhando com coordenadas negativas, tanto do eixo x como do eixo y.

Pesquisadora: Esses valores estão negativos [das coordenadas] [...], como você está me falando que é 1,25?

Kaique: É 1,25.

Pesquisadora: Por quê? [..]. Se as duas posições no eixo são negativas, por que você está me dando um valor positivo?

Kaique: Não sei, é isso que eu sei, pelo menos.

Pesquisadora: Por mais que você esteja na reta em relação aos negativos, por que sua medida é positiva?

Kaique: Porque não tem uma distância de $-4,45$, por exemplo.

Pesquisadora: Hum, então tem um critério para explicação.

Kaique: Não existe medida ao contrário.

Pesquisadora: Ao contrário?

Kaique: Negativa, no caso. 
Em seguida, o aluno Kaique começou a alterar o polígono que forma a camiseta, mas percebeu que havia pontos na gola que estavam sobrando (Figura 4a). Para não precisar apagar todo o polígono e reconstruir, ele buscou, na janela de álgebra, o polígono referente à camiseta, e retirou os pontos $\mathrm{J}$ e $\mathrm{L}$ da definição do polígono. Então, esses pontos estavam desassociados do polígono na representação gráfica (Figura 4b). Assim, verificamos que o aluno, mais uma vez, estabeleceu relações entre a representação algébrica e gráfica, e que compreendeu que, ao alterar a definição algébrica, a representação gráfica também se altera.

Figura 4: Polígono da camiseta com os pontos J e L e Polígono sem os pontos J e L

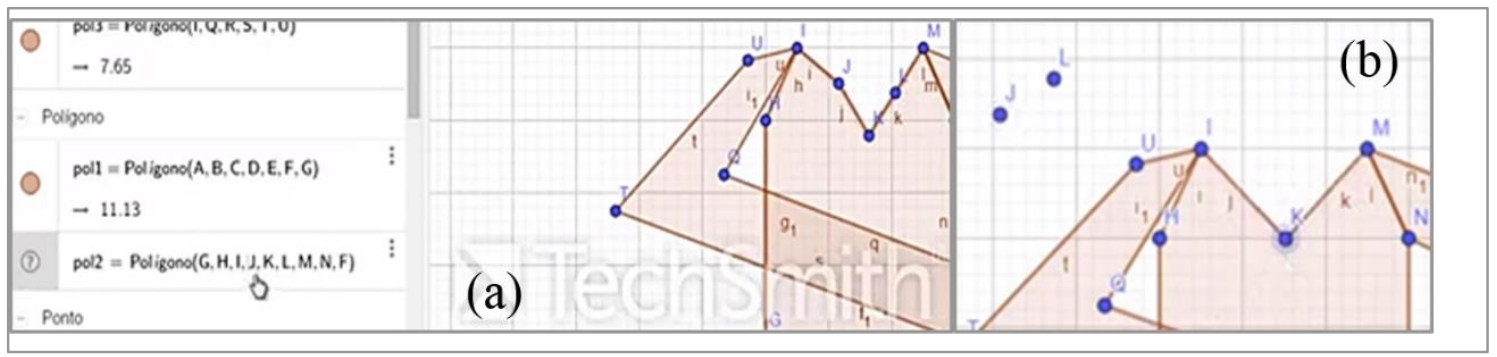

Fonte: Elaborada pelas autoras (2020)

Após alterar mais algumas coordenadas dos pontos do polígono, o aluno Kaique chamou a pesquisadora para explicar o que fez, como pode ser lido no excerto a seguir:

Kaique: Olhe, professora, totalmente simétrico, tanto a camisa quanto a calça.

Pesquisadora: Como você sabe que está simétrico?

Kaique: Porque do $M$ [com coordenadas $(-2.5,4)]$ ao $N$ [com coordenadas $(-2,3)]$ [...], o $N$ está -2 [em relação ao eixo x] e o M está -2,5 [com relação ao eixo x], ou seja, a distância entre eles é 0,5, e a diferença de altura [com relação ao eixo y] entre eles é 1; e esse aqui [com relação ao ponto $\mathrm{H}=(-5,3)$ e $\mathrm{I}=(-4.5,4)]$ e a distância, também é 0,5 [com relação ao eixo $\mathrm{x}$ ], e a distância de altura é 1 [com relação ao eixo y].

Pesquisadora: Certeza que tem 1 aqui [distância dos pontos H e I]?

Kaique: Uhum, olha aqui, o H está em 3 [com relação ao eixo y], e o I está em 4 [com relação ao eixo y].

Pesquisadora: Mas em relação a quem?

Kaique: Ao eixo y [...] e ao eixo x, a diferença deles é de 0,5.

Observamos que a pesquisadora questionou novamente sobre a simetria, e o aluno Kaique relacionou as coordenadas dos pontos $\mathrm{M}$ com $\mathrm{N}$ e $\mathrm{H}$ com I, da mesma forma que anteriormente, afirmando que são simétricos pelo fato de possuírem a mesma medida. $\mathrm{O}$ aluno mobilizou estratégias para buscar justificar e estabelecer relações entre as coordenadas de forma gráfica e algébrica, mas ainda não estabeleceu relações da simetria dos pontos com relação a um eixo de simetria específico. A fim de verificar se o aluno não relacionava a distância dos pontos apenas por meio das coordenadas, mas a distância real entre os pontos, a pesquisadora questionou o aluno Kaique, como pode ser observado no excerto abaixo. Então, o aluno Kaique buscou a ferramenta distância, comprimento ou perímetro disponível no software, e encontrou a real distância entre os pontos H e I. Dessa maneira, o aluno soube 
e utilizou corretamente a ferramenta disponível no artefato, e se apropriou das potencialidades que o software dispõe.

Pesquisadora: Quanto que você disse que tem do $H$ ao I?

Kaique: Do H ao I não tem 1[...], a distância paro o eixo x é meio e a distância pro eixo y é 1 .

Pesquisadora: Então, quanto mede essa distância [entre os pontos $\mathrm{H}$ e I]?

Kaique: Não sei, deixa eu ver [procura e seleciona a ferramenta distância, comprimento ou perímetro, clica sobre os pontos $\mathrm{H}=(-5,3)$ e $\mathrm{I}=(-4.5,4)$ e obtém o valor de 1,12$]$.

Observando que o aluno não estabeleceu relações com o eixo de simetria, a pesquisadora buscou, por meio de questionamentos, recordar o aluno sobre o conceito, induzindo que ele traçasse uma reta pelos pontos $\mathrm{C}$ e $\mathrm{K}$, já que ambos os pontos estavam no centro de cada polígono em que pertenciam com as mesmas coordenadas para x. Porém, o excerto a seguir revela que o aluno não recordou nem compreendeu inicialmente a ideia do eixo de simetria, pois associou o referencial para cada polígono como um ponto utilizado na construção (Figura 5).

Pesquisadora: [...] mas eu quero saber onde é o teu eixo, onde você está se localizando para ser simétrico?

Kaique: $O$ теи $K$ [ponto com coordenada (-3.5,3)], no caso?

Pesquisadora: Você precisa de um referencial para ter a simetria. Então, esse teu [ponto]

$K$ vai ser um referencial para tudo?

Kaique: Mais ou menos.

Pesquisadora: Mais ou menos por quê?

Kaique: É, o K está sendo o referencial, no caso.

Pesquisadora: E para você fazer a calça [polígono de baixo]?

Kaique: Eu usei o $C$ [ponto com coordenada $(-3.5,-0.5)]$ de calça.

Pesquisadora: $E$ o que você poderia fazer entre o $C$ e o $K$ ?

Kaique: Uma distância?

Pesquisadora: Não é necessariamente uma distância, eu quero saber o que você poderia fazer para ser a sua referência.

Figura 5: Ponto $\mathrm{C}$ e ponto $\mathrm{K}$

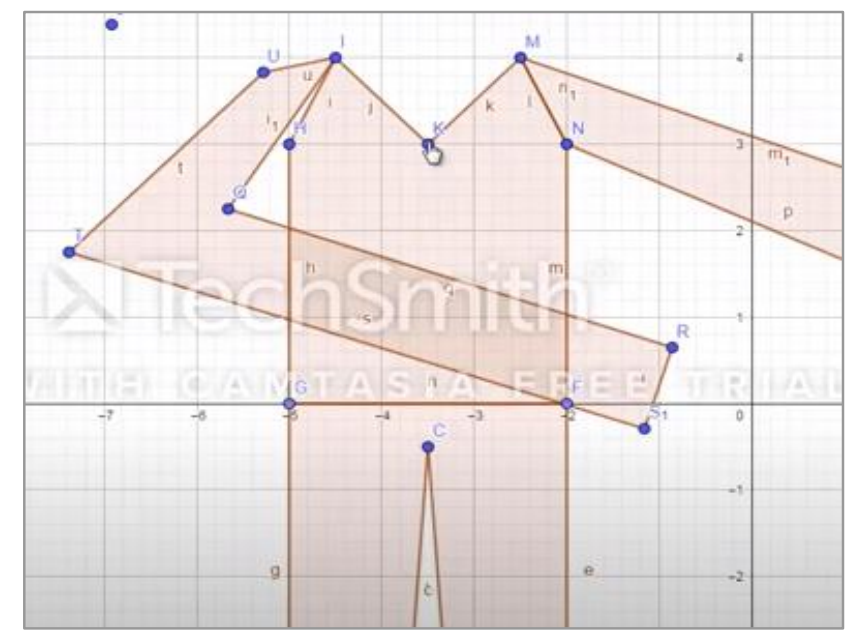

Fonte: Elaborada pelas autoras (2020) 
Utilizando a ferramenta ponto, o aluno, então, criou outro ponto, denominado jubileu, com as seguintes coordenadas (-3.5,0) (Figura 6). Inicialmente, a pesquisadora não compreendeu, e questionou o aluno sobre o que aquele ponto representava, e o aluno respondeu que seria o referencial. $\mathrm{O}$ aluno justificou que o ponto criado era o centro do corpo do boneco e, por isso, seria o referencial simétrico. A pesquisadora fez questionamentos para que o aluno refletisse sobre suas afirmações e verificasse se eram coerentes e corretas, conforme exposto a seguir.

Pesquisadora: E o que é esse ponto aí [Ponto jubileu $=(-3.5,0)]$ ?

Kaique: Esse é o referencial.

Pesquisadora: Por quê?

Kaique: Porque ele foi referência a esses dois aqui [dois polígonos] [...], porque esse, no caso, é o meio do corpo dele.

Pesquisadora: Tem certeza?

Kaique: Sim.

Pesquisadora: Por quê?

Kaique: Porque [...] ele está exatamente no meio.

Pesquisadora: Mas para ser referencial, ele deveria ser simétrico tanto para cima quanto para baixo. Está simétrico tanto em cima quanto embaixo?

Kaique: Não.

Pesquisadora: Então é o teu referencial?

Kaique: Mais ou menos.

Pesquisadora: Não, tem que escolher se é ou não é [...]. Essa distância é simétrica a essa distância [referindo-se à distância entre os pontos jubileu e K e entre jubileu e C]?

Kaique: Não.

Pesquisadora: Então, eles são simétricos?

Kaique: Não.

Pesquisadora: Então, ele é o ponto referencial?

Kaique: Não.

Figura 6: Ponto jubileu Figura

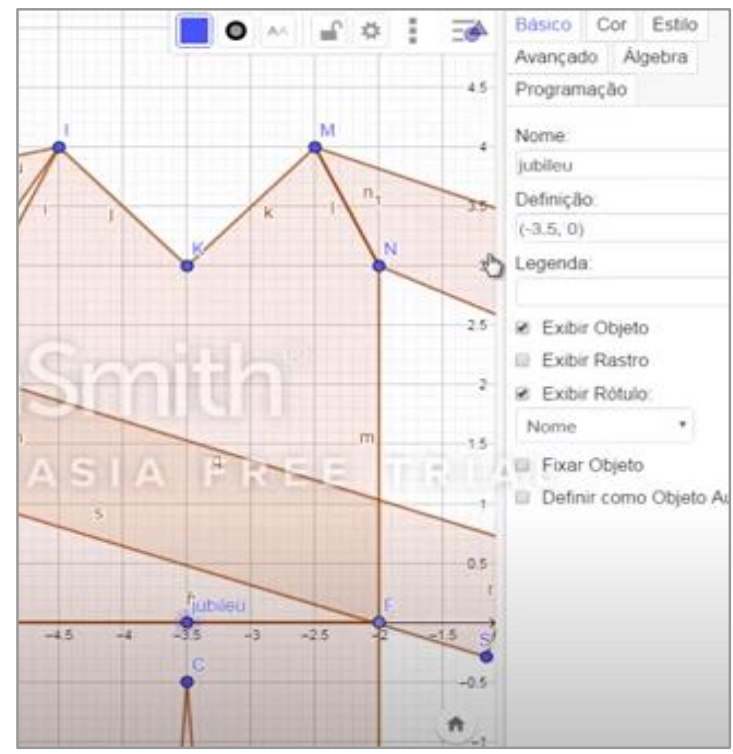

7: Reta F1 traçada a partir dos pontos K e C

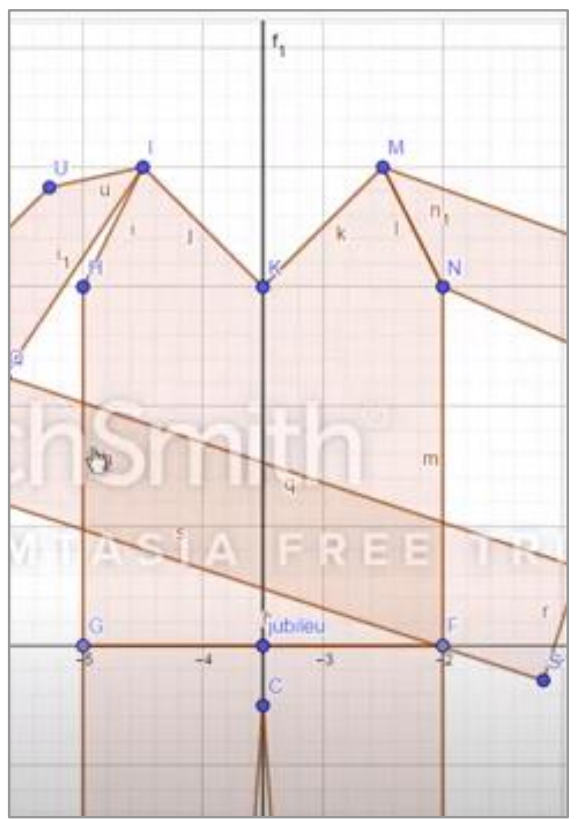

Fonte: Elaborada pelas autoras (2020) 
O aluno começou a tentar encontrar alguma ferramenta do software que auxiliasse a resolver essa questão. A pesquisadora sugeriu ao aluno que traçasse uma reta entre os pontos $\mathrm{K}$ e C (Figura 7). O aluno selecionou a ferramenta reta e clicou nos pontos $\mathrm{K}$ e C. Em seguida, a pesquisadora fez novamente questionamentos e explicações ao aluno, para que ele compreendesse que a reta traçada entre os pontos podia ser considerada como referencial simétrico dos polígonos. Assim, percebeu-se novamente que o aluno conseguiu utilizar corretamente a ferramenta e afirmou que compreendeu a ideia apresentada.

Pesquisadora: Se você traçar uma reta do ponto $K$ ao ponto $C$ [o aluno traça a reta], em relação à camiseta e à calça, ele não está simétrico?

Kaique: Sim.

Pesquisadora: Então, qual é o teu referencial?

Kaique: $O K$ e o $C$.

Pesquisadora: $O \mathrm{~K}$ e o $\mathrm{C}$ que estão formando o quê?

Kaique: $O F 1$ [reta criada a partir dos pontos $\mathrm{K}$ e C].

Pesquisadora: É a tua reta F1 que é o teu referencial. A partir dele que você vai ter que construir o corpo, o que acontecer de um lado vai ter que acontecer do outro.

Kaique: What? Não, eu entendi, entendi...

Pesquisadora: Essa distância é igual a quê [referindo-se à distância entre os pontos $\mathrm{K} \mathrm{e}$ $\mathrm{N}]$ ?

Kaique: Como assim?

Pesquisadora: $O$ ponto $K$ e o ponto $N$, ele tem que ter algum simétrico certo?

Kaique: $D o \mathrm{~K}$ ao $\mathrm{H}$.

Pesquisadora: Do K ao H... Olha, tem o ponto I e o ponto $M$, eles não são simétricos em relação à reta? [foi colocado um ponto $\mathrm{V}$ qualquer sobre a reta $\mathrm{F} 1$ ]

Pesquisadora: Se colocarmos a distância de I até V, é igual a 1 ; e de $M$ até $V$ é 1 , então ele está simétrico, agora.

Kaique: Exatamente.

Pesquisadora: [...] agora a sua reta é o referencial de simetria.

Aluno5: Entendi.

Para verificar se o aluno havia compreendido o que foi apresentado e explicado, a pesquisadora questionou sobre os braços do boneco, a cerca de como iria realizar o movimento de atirar com o arco e flecha se fossem simétricos, como pode ser lido no excerto a seguir.

Pesquisadora: E os braços são simétricos?

Kaique: Não, infelizmente. Porque eles vão ter que fazer isso aqui ó [faz um movimento com os braços imitando como iria atirar com arco e flecha].

Ainda na construção do corpo do boneco, faltava a cabeça e o pescoço. Para desenhar a cabeça, o aluno selecionou a ferramenta círculo, dados centro e raio, clicando na posição desejada sobre a reta F1 para o centro da circunferência, e selecionando o raio de 1. Depois, selecionou a ferramenta arco circular para formar o pescoço do boneco. Para fazer o desenho do pescoço no lado esquerdo, o aluno clicou sobre o ponto I, para ser o centro do arco circular; depois, em uma posição no segmento IK e, por fim, em uma posição da 
circunferência, que é a cabeça. Para fazer o desenho do pescoço no lado direto, o aluno clicou sobre o ponto M, para ser o centro do arco circular; depois, em uma posição da circunferência e, por fim, em uma posição no segmento MK. Dessa forma, o aluno conseguiu adaptar elementos matemáticos disponíveis no artefato para atender as suas necessidades na construção, mobilizando estratégias por meio do software.

Mas apesar de o aluno desenvolver a estratégia, os arcos circulares criados não ficaram simétricos em relação à reta F1 (Figura 8). A pesquisadora, então, questionou-o, como pode ser lido no excerto a seguir.

Pesquisadora: Mas esse teu ponto [referindo-se ao ponto V] não ficou exatamente igual ao outro [referindo-se ao ponto W].

Kaique: Eu sei, mas eu já mexo aqui para arrumar, espera aí [...], pronto.

Pesquisadora: E qual é o critério novamente, para esse ponto?

Kaique: Diferença de 1,5 para esse [entre os pontos V e W e a reta F1] e diferença de 2 para esse [entre os pontos $\mathrm{L}$ e $\mathrm{Z}$ e a reta $\mathrm{F} 1]$.

Pesquisadora: Tem certeza?

Kaique: Sim.

Pesquisadora: Então veja.

$\mathrm{O}$ aluno Kaique selecionou as ferramentas distância, comprimento ou perímetro, o ponto $\mathrm{V}$, e em seguida a reta $\mathrm{F} 1$, e obteve a distância de 0.3 . Após isso, selecionou o ponto W e, em seguida, a reta F1, e obteve a distância de 0.31 e se questionou:

Kaique: Como assim? Como isso é possível?

Figura 8: Distância entre os pontos $\mathrm{V}$ e $\mathrm{W}$ a reta $\mathrm{F} 1$

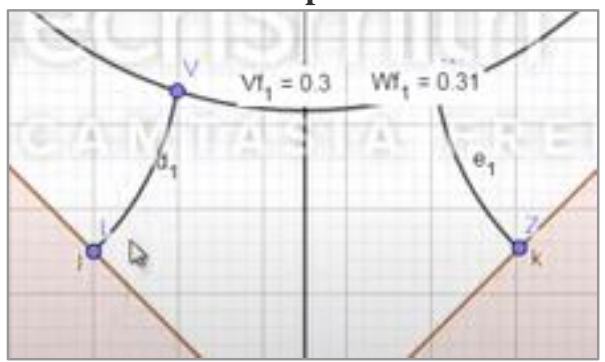

Fonte: Elaborada pelas autoras (2020)

Assim, com intuito de auxiliar o aluno, a pesquisadora questionou se não existia alguma outra ferramenta no software que o ajudasse a criar os dois arcos para o pescoço, de forma que fossem simétricos.

Pesquisadora: Você não acha uma ferramenta que pode te ajudar nessa parte de simetria? Kaique: Não.

Pesquisadora: Você procurou?

Kaique: Não, também não. 
Em seguida, o aluno começou a procurar alguma ferramenta que ajudasse, mas não encontrou nenhuma ferramenta intitulada simetria ou algo nesse sentido, de maneira explícita. A pesquisadora auxiliou, como pode ser observado no excerto abaixo.

Pesquisadora: Olhe ali... Reflexão em relação a uma...

Kaique: Reta.

Pesquisadora: E não é isso que você quer?

Kaique: Sim.

Pesquisadora: Que é refletir uma a outra [arcos] com relação à reta?

Kaique: Sim. Ah, entendi [usa a ferramenta selecionado a reta e o ponto V] [...]. Uau, meu V copiado!

Pesquisadora: Copiado não, refletido... E agora, quanto dá essa distância?

Kaique: [usa novamente a ferramenta Distância, Comprimento ou Perímetro entre os pontos V e a reta, e depois a reta e V'] 0,3 e 0,3. Muito obrigado, professora.

Figura 9: Reflexão de V em relação a reta F1 e Distância de V e F1 e V' e F1

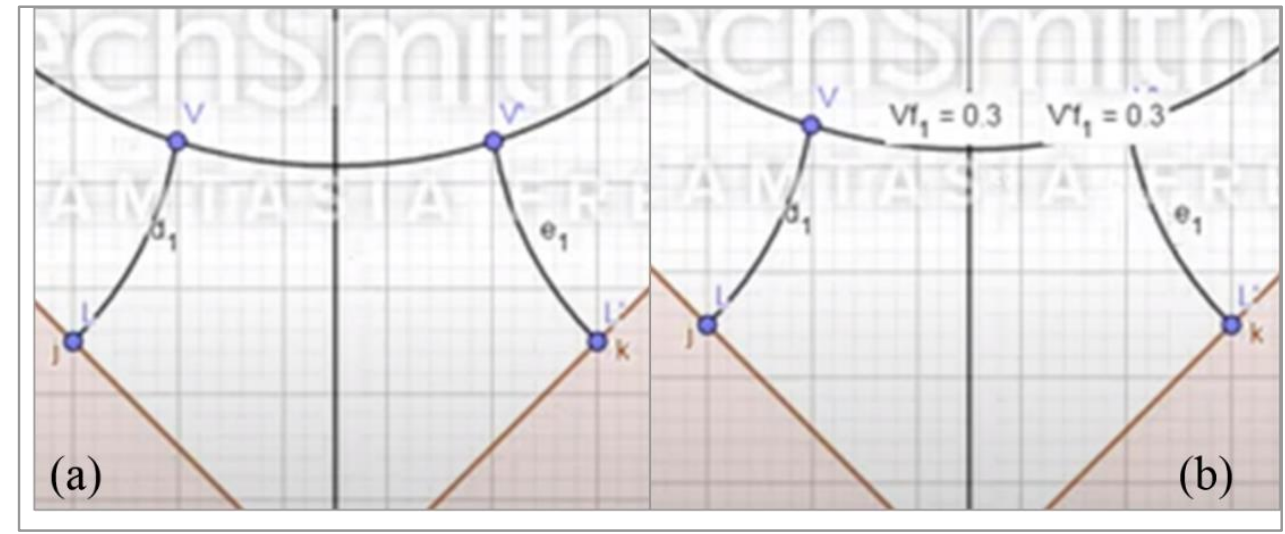

Fonte: Elaborada pelas autoras (2020)

Então, o aluno conseguiu criar o pescoço utilizando a ferramenta correta (Figuras 9a e 9b). Logo, construiu uma animação com um conceito diferente do apresentado na primeira construção da animação Arqueiro.

Em seguida, o aluno continuou a construção da animação, criando o $\operatorname{arco} \mathrm{e}$ programando para que a animação fosse finalizada (Figura 10). Para encerrar, a pesquisadora questionou o aluno sobre quais conteúdos matemáticos foram utilizados na construção.

Pesquisadora: E quais os conteúdos matemáticos que você utilizou?

Kaique: Simetria conta? [...] Simetria, pontos, controle deslizante, programação e polígonos. Só. [...]. E programação. 
Figura 10: Arqueiro 2 finalizado

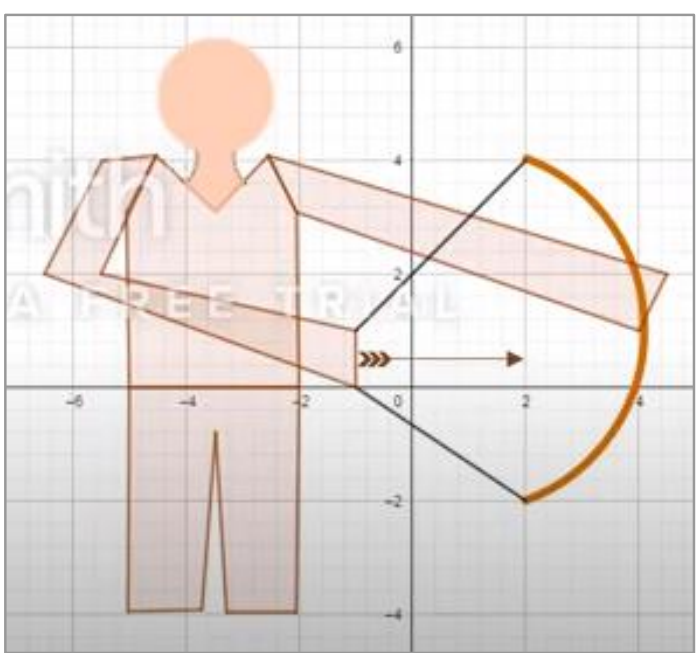

Fonte: Elaborada pelas autoras (2020)

Com base nos excertos e análises apresentados acima, sistematizamos as ações do aluno Kaique, relacionadas com a Gênese Instrumental no Quadro 3.

Quadro 3: Ações do aluno

\begin{tabular}{|c|c|}
\hline $\begin{array}{c}\text { Elementos da Gênese } \\
\text { Instrumental }\end{array}$ & $\begin{array}{c}\text { Descritores identificados na construção Arqueiro } 2 \text { pelo aluno } \\
\text { Kaique }\end{array}$ \\
\hline Artefato & $\begin{array}{l}\text { O GeoGebra antes do aluno iniciar a construção do cenário animado } \\
\text { Arqueiro. }\end{array}$ \\
\hline Instrumento & $\begin{array}{l}\text { O GeoGebra assumiu status de Instrumento quando, a partir da } \\
\text { animação do aluno Murilo, o aluno Kaique: } \\
\text { - Adaptou os polígonos que formavam a calça e a camiseta do boneco, } \\
\text { de maneira que ficassem simétricos em relação à reta criada pelos } \\
\text { pontos K e C; } \\
\text { - Substituiu as funções de primeiro grau por programações nos pontos } \\
\text { que se moviam; } \\
\text { - Criou uma circunferência para ser a cabeça do boneco; } \\
\text { - Criou arcos circulares para desenhar o pescoço; } \\
\text { - Utilizou a ferramenta reflexão em relação a uma reta para produzir } \\
\text { uma nova animação com simetria nas peças de roupa, cabeça e } \\
\text { pescoço do boneco; } \\
\text { - Relacionou a simetria por trás da utilização da ferramenta reflexão em } \\
\text { relação a uma reta. }\end{array}$ \\
\hline Esquemas & $\begin{array}{l}\text { O aluno mobilizou estratégias para que os segmentos AB e DE do } \\
\text { polígono da calça do boneco tivessem o mesmo tamanho, ou seja, a } \\
\text { mesma distância; } \\
\text { O aluno utilizou o conteúdo de simetria e conseguiu empregá-lo no } \\
\text { cenário; } \\
\text { O aluno conseguiu criar estratégias para a nova construção, tomando } \\
\text { como base a animação criada pelo aluno Murilo e adaptando com } \\
\text { fundamento nas suas experiências; } \\
\text { O aluno criou o cenário animado Arqueiro } 2 \text { com potencial para o } \\
\text { conteúdo de simetria, coordenadas cartesianas, expressões algébricas e } \\
\text { lógica matemática. }\end{array}$ \\
\hline Instrumentação & $\begin{array}{l}\text { O aluno: } \\
\text { - Desenvolveu a proposta manipulando as ferramentas do artefato e } \\
\text { estabeleceu relações entre a representação algébrica e gráfica quando: } \\
\text { O Alterou as coordenadas na janela algébrica para modificar o } \\
\text { polígono no plano cartesiano; }\end{array}$ \\
\hline
\end{tabular}




\begin{tabular}{|l|l|}
\hline & O Retirou os pontos J e L da definição do polígono na janela \\
& algébrica para que os pontos se desassociassem da representação \\
do polígono na janela gráfica; & O Realizou cálculos com base nas coordenadas algébricas para saber \\
& a distância entre os pontos no plano cartesiano; \\
- Realizou todo o processo da construção do cenário e utilizou as & ferramentas corretas, como ponto; reta; círculo, dados centro e raio; \\
& arco circular; polígono; distância, comprimento ou perímetro; $e$ \\
& reflexão em relação a uma reta fornecidas pelo artefato para chegar \\
& no objetivo; \\
& - Utilizou o artefato como meio para a realização e concretização da \\
& tarefa, e mobilizou conhecimentos matemáticos. \\
\hline O aluno: \\
• Compreendeu o funcionamento das ferramentas e elementos, como \\
caixa de entrada e caixa de definição de um ponto, e manipulou o \\
artefato; \\
• Iniciou um processo de personalizar e adaptar o artefato para auxiliar \\
na estratégia de deixar a calça e a camiseta do boneco simétricos, \\
mesmo não utilizando a ferramenta correta inicialmente.
\end{tabular}

Fonte: Elaborado pelas autoras, 2020

\section{Considerações Finais}

As análises da construção do cenário animado pelo aluno Kaique evidenciam que o GeoGebra favoreceu a realização e concretização da tarefa, mobilizando conhecimentos matemáticos, especialmente relacionados à simetria, coordenadas cartesianas, reflexão e elementos geométricos e representações algébricas, em que destacamos a relação que estabelece entre álgebra e geometria. O GeoGebra, para o aluno Kaique, passou de artefato a instrumento ao ser adaptado para poder utilizá-lo para conseguir construir o cenário, utilizando conhecimentos matemáticos para isto. Para tanto, precisou desenvolver esquemas de utilização do GeoGebra, em que teve que elaborar estratégias e conjecturas, testando-as, validando-as ou refutando-as, a partir das informações que inseria no software e do retorno que visualizava, que lhe fazia rever as estratégias traçadas.

Nesse sentido, destacamos elementos da instrumentação, visto que o aluno construiu a animação Arqueiro 2 no GeoGebra desenvolvendo meios para solucionar os problemas encontrados usando os recursos disponíveis no software. Também elementos da instrumentalização, dado que o aluno conseguiu localizar e utilizar ferramentas como ponto, reta e polígono corretamente para a construção da animação, relacionando a representação algébrica e geométrica para realizar modificações em sua construção e atingir o objetivo proposto.

Evidenciamos, ainda, que por meio da construção desse novo cenário foi possível observar que o aluno, inicialmente, estava usando o conceito de simetria, mas sem 
compreendê-lo, porque estava criando elementos por meio de testes e mobilizando outros conteúdos matemáticos para tal. Entretanto, por meio dos questionamentos da pesquisadora, que lhe chamou a atenção para a ferramenta reflexão em relação a uma reta, o aluno conseguiu compreender o conceito de simetria e passou a utilizar uma nova ferramenta do GeoGebra. Portanto, ele se apropriou de uma nova ferramenta do artefato e utilizou-a para deixar o pescoço do boneco simétrico. Porém, destacamos o papel do professor para que aluno compreendesse novos conceitos, atuando como mediador cultural do conhecimento matemático.

Nesse sentido, percebemos que o aluno relacionou a matemática com as ferramentas disponíveis no GeoGebra, construindo um novo cenário utilizando diferentes conteúdos de matemática, que compreendeu a partir da construção realizada.

Agradecimentos: Agradecemos à PRPPG (Pró-Reitoria de Pesquisa e PósGraduação) da Unespar e à Fundação Araucária pelo apoio financeiro recebido.

\section{Referências}

Abar, C. A. A. P., \& Alencar, S. V. (2013). A Gênese Instrumental na Interação com o GeoGebra: uma proposta para a formação continuada de professores de Matemática. Bolema, 27(46), 349-365. https://doi.org/10.1590/S0103-636X2013000300002

Bellemain, F. B., \& Trouche, L. L. (2018). Compreender o trabalho do professor com os recursos de seu ensino, um questionamento didático e informático. Caminhos da Educação Matemática em Revista/Online, 9(1), 105-144.

Bittar, M. A. (2011). Abordagem Instrumental Para O Estudo Da Integração Da Tecnologia Na Prática Pedagógica Do Professor De Matemática. Educar Em Revista, 1, 157-171. http://dx.doi.org/10.1590/S0104-40602011000400011

Brasil. (1998). Secretaria de Educação Fundamental. Parâmetros curriculares nacionais: Matemática / Secretaria de Educação Fundamental. Brasília: MEC / SEF. 148 p.

Brasil. (2006). Secretaria de Educação Básica. Orientações curriculares para o ensino médio: Ciências da natureza, matemática e suas tecnologias. Brasília: Ministério da Educação, Secretaria de Educação Básica, 2006. (Orientações curriculares para o ensino médio, v.2) p. 69-80.

Brasil. (2017). Base Nacional Comum Curricular. MEC.

Bueno, A. C., \& Basniak, M. I. (2018). Contribuições da construção de animações no software GeoGebra para a mobilização do conhecimento matemático de alunos com AH/SD. XIV Semana Da Matemática 2018. União da Vitória - PR. https://semanadamatematicaunesparuv.webnode.com/anais-2018/ 
García-Cuéllar, D. \& Martínez-Miraval, M. (2018). Estudio del proceso de Génesis Instrumental del artefacto simbólico función exponencial. Revista Transformación, $14(2), 252-261$.

García-Cuéllar, D. \& Salazar, J.V.F (2019). Estudio de la génesis instrumental del artefacto simbólico simetría axial. TANGRAM - Revista de Educação Matemática, 2(3), 28-48. doi: https://doi.org/10.30612/tangram.v2i3.9068

Matta, A. E. R., Silva, F. P. S., \& Boaventura, E. M. (2014). Design-based research ou pesquisa de desenvolvimento: metodologia para pesquisa aplicada de inovação em educação do século XXI. Revista da FAEEBA - Educação e Contemporaneidade, 23(42), 23-36. http://dx.doi.org/10.21879/faeeba2358-0194.2014.v23.n42.p\%25p

Neto, A. L. X., Silva, \& M. J. F. da. (2017). Gênese Instrumental do artefato simbólico função de uma variável real definida por várias sentenças matemáticas em um ambiente não digital. Revista Iberoamericana de Educação Matemática. 51, 107-125.

Notare, M. R., \& Basso, M. V. de A. (2017a). Gênese Instrumental Pessoal e Conceitos Matemáticos em Processo de Criação com o GeoGebra. RENOTE - Novas Tecnologias na Educação, 15(2), 1-10. https://doi.org/10.22456/1679-1916.79238

Notare, M. R., \& Basso, M. V. De A. (2017b). Gênese Instrumental do GeoGebra na Formação de Professores. Zetetiké, 25(2), 324-344. http://dx.doi.org/10.20396/zet.v25i2.8647864

Pachêco, F. F. F., Silva, A. D. P. R. da., Araújo, A. F. Q., Silva, A. S. da., \& Ferreira, A. G. (2018). A gênese instrumental por alunos do $6^{\circ}$ ano do ensino fundamental do poly no estudo dos poliedros regulares [Ponencia]. V Congresso Nacional de Educação, Olinda - Pernambuco, Brasil. https://editorarealize.com.br/edicao/detalhes/anais-v-conedu

Paraná. (2008). Secretaria de Estado da Educação. Diretrizes curriculares da educação básica: matemática. Curitiba: SEED.

Prieto G, J. L., \& Araujo. R. E. G. (2019). Contribuições da Teoria da Objetivação ao estudo da aprendizagem geométrica em contextos de elaboração de simuladores com o GeoGebra. Asociación Aprender en Red. Venezuela.

Rabardel, P. (2002). Pessoas e tecnologia: uma abordagem cognitiva dos instrumentos contemporâneos. Université paris 8. hal-01020705.

Rabardel, P. (1995). Les hommes et les technologies: une approche cognitive des instruments contemporains. Armand Colin.

Autores

Adrieli Cristine Bueno

Graduanda do curso de Licenciatura em Matemática da UNESPAR - Campus de União da Vitória. Temas de pesquisa: Tecnologia na Educação Matemática. E-mail: adrielicbueno@gmail.com

Maria Ivete Basniak

Doutora em Educação pela Universidade Federal do Paraná. Professora Adjunta da Universidade Estadual do Paraná. Temas de pesquisa: Tecnologia e Educação Matemática, Práticas Pedagógicas e Formação de Professores que ensinam Matemática, Políticas Educacionais. Email: maria.basniak@ies.unespar.edu.br 